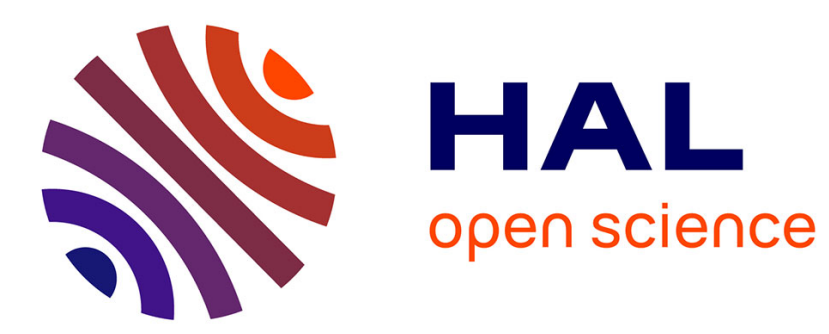

\title{
Database Approach for Laminar-Turbulent Transition Prediction on Heated Wall
}

Julien Saint-James, Hugues Deniau, Olivier Vermeersch, Estelle Piot

\section{To cite this version:}

Julien Saint-James, Hugues Deniau, Olivier Vermeersch, Estelle Piot. Database Approach for Laminar-Turbulent Transition Prediction on Heated Wall. AIAA SCITECH 2020, Jan 2020, Orlando, United States. 10.2514/6.2020-1035 . hal-02443619

\section{HAL Id: hal-02443619 https://hal.science/hal-02443619}

Submitted on 17 Jan 2020

HAL is a multi-disciplinary open access archive for the deposit and dissemination of scientific research documents, whether they are published or not. The documents may come from teaching and research institutions in France or abroad, or from public or private research centers.
L'archive ouverte pluridisciplinaire HAL, est destinée au dépôt et à la diffusion de documents scientifiques de niveau recherche, publiés ou non, émanant des établissements d'enseignement et de recherche français ou étrangers, des laboratoires publics ou privés. 


\title{
Database Approach for Laminar-Turbulent Transition Prediction on Heated Wall
}

\author{
Julien Saint-James* , Hugues Deniau, Olivier Vermeersch and Estelle Piot ${ }^{\dagger}$ \\ ONERA/DMPE, Université de Toulouse \\ F-31055 Toulouse - France
}

A database approach is developed to predict laminar-turbulent transition of a boundary layer over a heated wall. This approach is based on the local linear stability theory (LLST). The database method is an expansion of the ONERA's so-called Parabolas method. Growth rate instabilities are stored in a database indexed on relevant flow parameters. The transition position is determined via the so-called $\mathrm{N}$-factor method. First validations are made on exact stability computations. In the final paper validation will be made on a 2D ONERAD airfoil equipped with hot skin. RANS numerical results for this test case will be compared to experimental results.

\section{Nomenclature}

$\sigma \quad=\quad$ Amplification rate of a given mode

$s=$ Curvilinear abscissa along a streamline

$s_{0} \quad=\quad$ s of first amplified mode (critical abscissa)

$\delta=$ Boundary layer thickness

$\delta_{1}=$ Incompressible displacement thickness

$\theta_{11}=$ Incompressible momentum thickness

$\Delta \quad=$ Enthalpy thickness

$\mathrm{N} \quad=\mathrm{N}$-factor

$\mathrm{N}_{\mathrm{T}}=$ Transitional $\mathrm{N}$-factor value

$F=$ Dimensionless frequency $\left(F=2 \pi f v_{e} / u_{\mathrm{e}}^{2}\right)$

$f \quad=$ Physical frequency

$M_{\mathrm{e}}=$ Mach number at the boundary layer edge

$\omega=$ Angular frequency

$\operatorname{Re}_{\delta_{1}}=$ Reynolds number based on the displacement thickness $\delta_{1}$

$\operatorname{Re}_{\theta_{11}}=$ Reynolds number based on the momentum thickness $\theta_{11}$

$\operatorname{Re}_{\Delta}=$ Reynolds number based on the enthalpy thickness $\Delta$

$\mathrm{C}_{\mathrm{f}} \quad=$ Skin-friction coefficient

$\mathrm{C}_{\mathrm{h}} \quad=$ Heat flux coefficient

$H_{i} \quad=$ Incompressible shape factor

$T_{u} \quad=\quad$ Free-stream turbulence level

$u_{\mathrm{e}} \quad=$ Velocity at the boundary layer edge

$\varphi^{*} \quad=$ Dimensionless quantity corresponding to $\varphi$

$v_{\mathrm{e}}=$ Boundary layer edge kinematic viscosity

$\alpha, \beta=$ Longitudinal and transverse wave number

$x=$ Longitudinal direction

$y=$ Wall normal direction

$\Phi_{w} \quad=$ Wall heat flux

$T_{\mathrm{W}} \quad=$ Wall temperature

$T_{\mathrm{f}}=$ Friction temperature or adiabatic wall temperature

$h_{i} \quad=$ Stagnation enthalpy

$h_{i e}=$ Stagnation enthalpy at the boundary layer edge

*PhD Candidate, Multi-Physics for Energetics Department (DMPE- ITAC) Onera Toulouse.

${ }^{\dagger}$ Research engineer, Multi-Physics for Energetics Department (DMPE- ITAC) Onera Toulouse. 


\section{Introduction}

Modern wing profile design aims at reducing aircraft drag to lower fuel consumption. Laminar to turbulent transition prediction is therefore of major practical interest because of the increase in friction drag accross the transition position. Prediction of this position has thus become a challenge in modern numerical fluid dynamics and an extensive use of the so-called $\mathrm{N}$-factor method has been made for the last five decades [1]. In the case of natural transition, the boundary layer of a laminar flow is contamined through a process called boundary layer receptivity. The linear amplification of these modes is followed by non-linear interactions that trigger breakdown to transition [2].

The $\mathrm{N}$-factor method consists in an integration of the spatial amplification rate of each mode along the external boundary layer streamline. Amplification rates are given by the local linear stability theory (LLST) and transition is assumed to take place where the most amplified mode's $\mathrm{N}$-factor - highest $\mathrm{N}$-factor at a given location - reaches a prescribed transitional value [3] [4]. As it is based on a local linear theory, this method does not account for some phenomena, such as non-parallel effects, receptivity process and non-linear mechanisms. The exact stability results may be obtained via the classical Orr-Sommerfeld equation but solving it is generally time-consuming.

Three decades ago ONERA has therefore developed a simplified method to compute amplification rates. It is based on a simple analytic approximation of the growth rates, function of the Reynolds number and a dimensionless frequency [5]. The different coefficients used in the analytic expressions are tabulated with respect to some relevant flow parameters. This method, called the Parabolas method, is refered to as a database method and was firstly developed for two-dimensional incompressible flows over adiabatic walls. It has been extended to compressible three-dimensional flows [6] with a correction for wall temperature effects (flow over "cold wall") [7]. This extension distinctively models crossflow (CF) and Tollmien-Schlichting (TS) instabilities.

To avoid ice accretion on the leading edges of wings or nacelles, de-icing or anti-icing systems are used, which heat the wall in this area. In the litterature, two temperatures are defined [8]: $T_{\mathrm{w}}$ the wall temperature and $T_{\mathrm{f}}$ the friction temperature or the adiabatic wall temperature. The heated wall is caracterized by a ratio $T_{\mathrm{w}} / T_{\mathrm{f}}$ greater than 1 . An adiabtic wall is characterized by $T_{\mathrm{w}} / T_{\mathrm{f}}=1$ and a cold wall by $T_{\mathrm{w}} / T_{\mathrm{f}}<1$. The laminar to turbulent transition will take place sooner for a heated wall than for an adiabatic one since the boundary layer is destabilized over a heated wall whereas it is stabilized when the wall is cold [9].

In this paper, we propose to extend the Parabolas method to compressible flows over a heated wall. This expansion will be related to TS instabilities as the CF ones are independant of the wall temperature [10].

\section{Determination of the transition location}

All developements presented in this paper are made for compressible two-dimensional mean flow. Only TS waves will be taken into account in this work. For two-dimensional mean flow this type of instability is mainly two-dimensional at low Mach number and can become three-dimensional in the case of adverse pressure gradients or when compressibility effects become significant (transonic conditions for instance).

\section{A. Problem formulation and $\mathrm{N}$-factor method}

\section{Linear local stability theory and stability diagram}

Natural transition occurs when the boundary layer is disturbed by a set of perturbations (noise, external turbulence, ...) which turn into a superposition of normal modes through a process called receptivity [11]. A local spatial stability analysis allows the determination of the most unstable modes. In compressible case, velocity, pressure, temperature, viscosity and density are thus written as

$$
\varphi^{*}=\bar{\varphi}+\varphi^{\prime}
$$

where $\varphi^{*}$ is the dimensionless quantity, $\bar{\varphi}$ its mean value and $\varphi^{\prime}$ its fluctuation which modal form yields

$$
\left.\varphi^{\prime} *=\underline{\varphi^{*}}\left(y^{*}\right) e^{\sigma^{*} x^{*}} e^{i\left(\alpha^{*} x^{*}+\beta^{*} z^{*}-\omega^{*} t^{*}\right)}+C . C . \quad \text { (C.C. }=\text { Complex Conjugate }\right)
$$

$\varphi^{*}$ being the eigenfunction, $\sigma^{*}$ the dimensionless growth or amplification rate, $\alpha^{*}$ and $\beta^{*}$ the longitudinal and transverse dimensionless wave numbers. These last three quantities are defined by

$$
\sigma^{*}=\sigma \delta_{1} \quad, \quad \alpha^{*}=\alpha \delta_{1} \quad \text { and } \quad \beta^{*}=\beta \delta_{1}
$$


where the incompressible displacement thickness $\delta_{1}$ is defined by

$$
\delta_{1}=\int_{0}^{\delta}\left(1-\frac{u}{u_{\mathrm{e}}}\right) d y
$$

$\omega^{*}$ is the dimensionless angular frequency given by

$$
\omega^{*}=\omega \frac{\delta_{1}}{u_{\mathrm{e}}} .
$$

All these quantities are real in the case of spatial stability study and the $x$-direction is the only direction of instability amplification under the parallel flow assumption. A mode is amplified when its amplification rate $\sigma^{*}$ is positive.

Stability analysis can be carried out by injecting the form of instabilities proposed in equation (2) into the compressible Navier-Stokes equations and linearizing the resulting system. This leads to the generalized Orr-Sommerfeld equations (or the local linear stability equations [9]), which can be numerically solved -for a given mean flow - to obtain the amplification rates of several frequencies as function of $\operatorname{Re}_{\delta_{1}}$ and $\omega^{*}$, where $\operatorname{Re}_{\delta_{1}}$ is the Reynolds number based on the incompressible displacement thickness $\delta_{1}$.

A stability diagram, such as presented in figure 1 a can be drawn to represent the frequency domain where instabilities are amplified. In this diagram, angular frequency $\omega^{*}$ is the ordinates and $\operatorname{Re}_{\delta_{1}}$ is the abscissae. As a consequence, iso-frequencies - iso- $F$ - are straight lines passing through the origin $\left(\omega^{*}=F \operatorname{Re}_{\delta_{1}}\right)$. The particular set of points defined by $\sigma^{*}=0$ is called the neutral curve. The critical point is the location of the neutral curve with the lowest $\operatorname{Re}_{\delta_{1}}$.

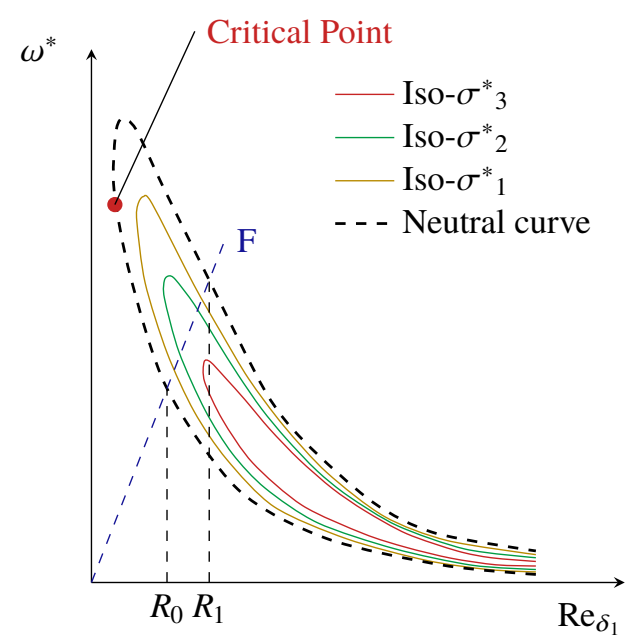

(a) Stability diagram and iso- $F$

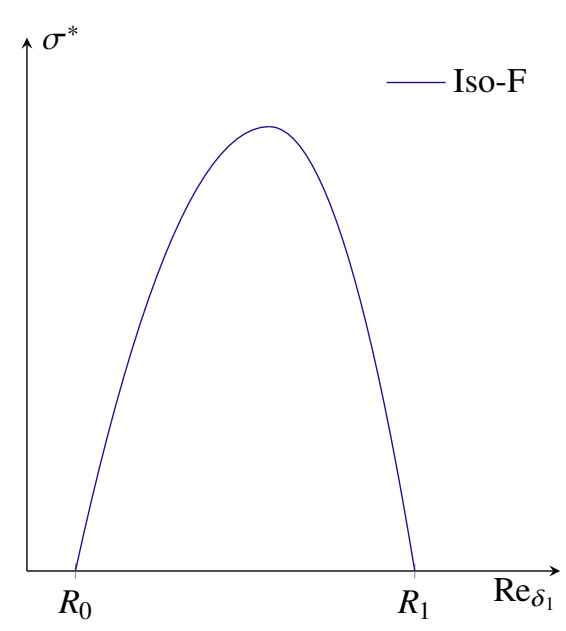

(b) Amplification rate for $F$

Fig. 1 Example of stability diagram $\left(\sigma^{*}{ }_{3}>\sigma^{*}{ }_{2}>\sigma^{*}{ }_{1}>0\right)$

Arnal [5] observed that the amplification rate, presented in figure $1 \mathrm{~b}$, of a given $F$ as a function of $\operatorname{Re}_{\delta_{1}}$ can be approximated by two half parabolas, as explained in the next section.

\section{Viscous inflectional instabilities}

Here we describe the instabilities that are considered in our case : viscous-inflectional instabilities. The corresponding type of stability diagram is presented in figure 2. Viscous instabilities are due to the destabilizing effect of viscosity, as established by Prandtl [12]. Its influence is more important at moderate Reynolds number.

Stability equations for an infinite Reynolds number show that the existence of a generalized inflection point on the boundary layer profile is a necessary condition to the existence of a range of unconditionally amplified frequencies [13]. This results in an upper branch that tends toward a constant non-null angular frequency on the neutral curve (figure 2). This type of instabilities are called inflectional. 


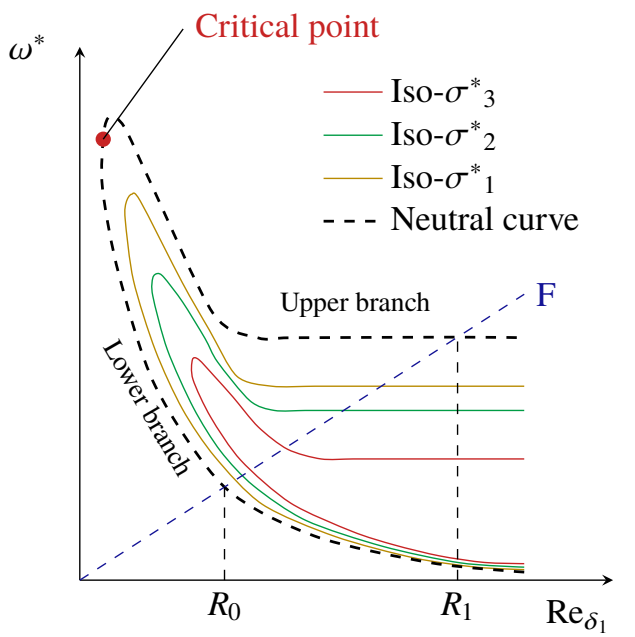

Fig. 2 Viscous-inflectional instabilities

The generalized inflection point is defined at altitude $y_{\mathrm{ig}}$ by

$$
\left.\frac{d}{d y^{*}}\left(\rho \frac{d u^{*}}{d y^{*}}\right)\right|_{y=y_{\mathrm{ig}}}=0
$$

and may appear because of two factors:

- the mean velocity inflection point, that may be caused by an adverse pressure gradient;

- the density profile in the case of higher Mach numbers or heated wall, even when the mean velocity profile does not present an inflection point.

In 2D cases, the outbreak of the viscous-inflectional instabilities may be observed if the generalized inflection point is high enough in the boundary layer profile.

\section{N-factor method}

The $\mathrm{N}$-factor method is a technique where the total amplification $\mathrm{N}$ of each amplified mode is computed. Let us consider a given mode of initial amplitude $A_{0}$ at position $s_{0}$, that increases up to an amplitude $A$ at a position $s$. This mode's exponential growth gives the expression of $\mathrm{N}$ integrated over the external streamline:

$$
\mathrm{N}(s, F)=\ln \frac{A}{A_{0}}=\int_{s_{0}}^{s} \sigma^{*}(F, \eta) d \eta
$$

A semi-empiric correlation established by Mack [9] gives an estimation of the transitional $\mathrm{N}$-factor $\mathrm{N}_{\mathrm{T}}$ function of the external turbulence level:

$$
\mathrm{N}_{\mathrm{T}}=-8,43-2,4 \ln \left(T_{u}\right) \quad 10^{-3}<T_{u}<10^{-2}
$$

where $T_{u}$ is the external turbulence level. The $\mathrm{N}$-factor of several modes are computed and the curve given by $\max _{\mathrm{F}}(\mathrm{N})-$ called the envelope - is obtained (Figure 3). If at a given position on the airfoil the envelope reaches $\mathrm{N}_{\mathrm{T}}$, transition is considered to occur and the transition position is noted $x_{\mathrm{tr}}^{*}$.

In order to compute the value of $\mathrm{N}$, the amplification rate $\sigma^{*}$ of each mode has to be known at each station of the profile. To do so, one can either use exact stability results (via the generalized Orr-Sommerfeld equations for instance) or, as it is done here, use the so-called database method developed at ONERA.

\section{B. Database Approach for viscous-inflectional instabilities in attached flows}

When the wall is heated, a generalized inflection point appear in the boundary layer profile. This leads to viscous-inflectional instabilities. As illustrated in figure 4 the amplification rate are expressed analytically wih four 


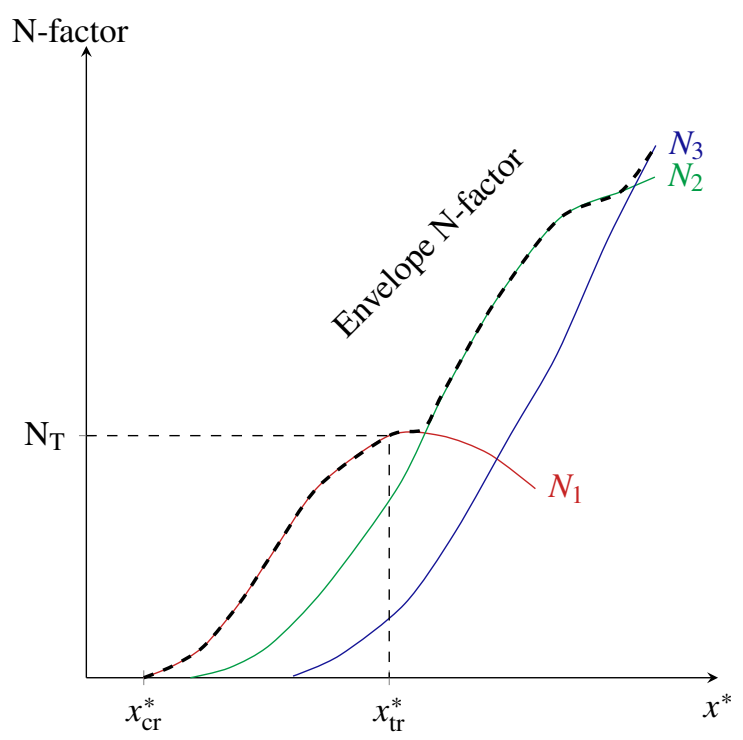

Fig. 3 Envelope technique for the $\mathrm{N}$-factor method with three frequencies

half-parabolas, yielding

$$
\begin{array}{rlrl}
\frac{\sigma^{*}{ }_{v}}{\sigma_{M \mathrm{v}}} & =1-\left[\frac{\operatorname{Re}_{\delta_{1}}-R_{\mathrm{Mv}}}{R_{\mathrm{kv}}-R_{\mathrm{Mv}}}\right]^{2} & \text { with } & R_{\mathrm{kv}}= \begin{cases}R_{0 \mathrm{v}} & \text { if } \operatorname{Re}_{\delta_{1}}<R_{\mathrm{Mv}} \\
R_{1 \mathrm{v}} & \text { else }\end{cases} \\
\frac{\sigma^{*}{ }_{i}}{\sigma_{M \mathrm{i}}}=1-\left[\frac{\operatorname{Re}_{\delta_{1}}-R_{\mathrm{Mi}}}{R_{\mathrm{ki}}-R_{\mathrm{Mi}}}\right]^{2} & \text { with } & R_{\mathrm{ki}}= \begin{cases}R_{0 \mathrm{i}} & \text { if } \operatorname{Re}_{\delta_{1}}<R_{\mathrm{Mi}} \\
R_{1 \mathrm{i}} & \text { else }\end{cases}
\end{array}
$$

where the subscript " $v$ " appoint for viscous instabilities and the subscript " $\mathrm{i}$ " for the inflectional ones.

A linear correction is added for a better modelisation of the decrease of the inflectional amplification rate at high $\mathrm{Re}_{\delta_{1}}$ values. The amplification rate $\sigma^{*}$ is given by $\sigma^{*}=\max \left(\sigma^{*}{ }_{v}, \sigma^{*}{ }_{i}\right)$.

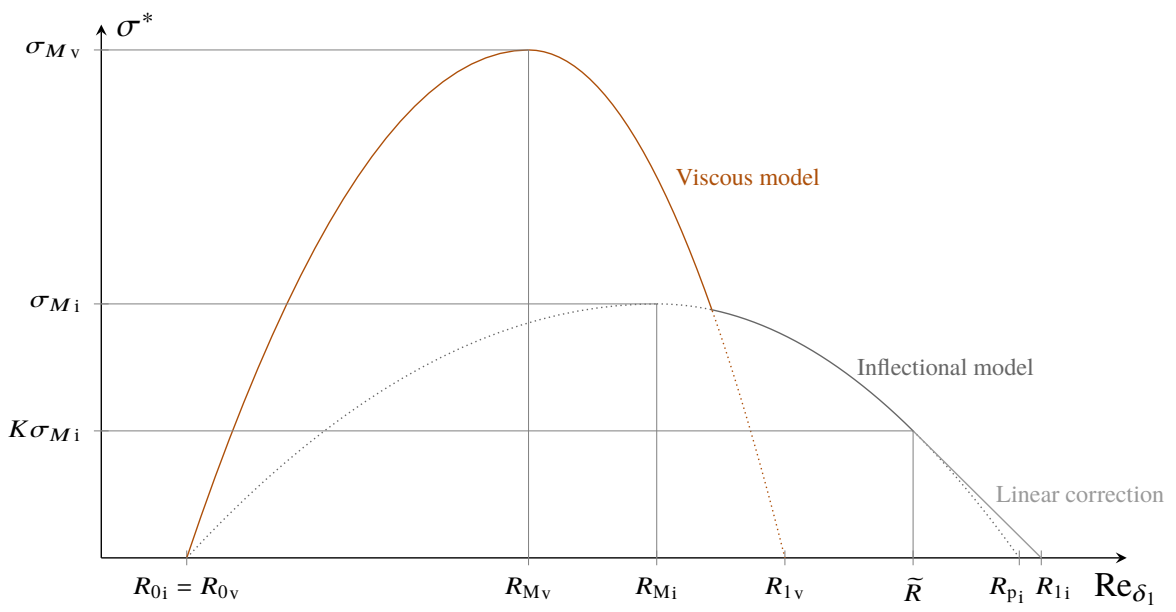

Fig. 4 Qualitative representation of viscous-inflectional amplification rates

The intersection between the inflectional model and the linear correction is done when $\sigma_{i}=K \sigma_{M \mathrm{i}}$ with $K=0.5$ at $\operatorname{Re}_{\delta_{1}}=\tilde{R}$ with a tangent equality condition. The linear law is given by

$$
\frac{\sigma_{i}}{\sigma_{M \mathrm{i}}}=\left(\operatorname{Re}_{\delta_{1}}-R_{1 \mathrm{i}}\right) \frac{K}{\tilde{R}-R_{1 \mathrm{i}}} \quad \text { with } \quad \tilde{R}=\frac{2(1-K) R_{1 i}+K R_{M i}}{2-K}
$$


The parabolas parameters $\sigma_{M \mathrm{v}}, \sigma_{M \mathrm{i}}, R_{\mathrm{Mv}}, R_{\mathrm{Mi}_{\mathrm{i}}}, R_{0 \mathrm{v}}, R_{0 \mathrm{i}}, R_{1_{\mathrm{v}}}$ and $R_{1_{\mathrm{i}}}$ are function of $F$ as follows

$$
\begin{aligned}
& \sigma_{M \mathrm{v}}=\min \left(A_{\mathrm{Mv}}\left(1-\frac{F}{F_{\mathrm{Mv}_{\mathrm{v}}}}\right), \sigma_{M 1}\right) \\
& \sigma_{M \mathrm{i}}=A_{\mathrm{Mi}}\left(1-\frac{F}{F_{M \mathrm{i}}}\right) \\
& R_{\mathrm{Mv}_{\mathrm{v}}}=K_{M \mathrm{v}}\left(10^{5} F\right)^{-E_{M \mathrm{v}}} \\
& R_{\mathrm{Mi}}=\max \left(R_{\mathrm{Mv}}, K_{M \mathrm{i}}\left(10^{5} F\right)^{-E_{M \mathrm{i}}}\right) \\
& R_{0 \mathrm{v}}=R_{\mathrm{Mv}}\left[1-A_{0 \mathrm{v}}\left(1-\frac{F}{F_{0 \mathrm{v}}}\right)\right] \\
& R_{0 \mathrm{i}}=R_{0 \mathrm{v}} \\
& R_{1 \mathrm{v}}=K_{1 \mathrm{v}}\left(10^{5} F\right)^{-E_{1 \mathrm{v}}} \\
& R_{1 \mathrm{i}}=K_{1 \mathrm{i}}\left(10^{5} F\right)^{-E_{1 \mathrm{i}}}
\end{aligned}
$$

The 15 coefficients $\sigma_{M \mathrm{l}}, A_{\mathrm{Mv}}, A_{\mathrm{Mi}}, F_{\mathrm{Mv}}, F_{\mathrm{Mi}}, K_{M \mathrm{v}}, K_{M \mathrm{i}}, E_{M \mathrm{v}}, E_{M \mathrm{i}}, A_{0 \mathrm{v}}, F_{0 \mathrm{v}}, K_{1 \mathrm{v}}, K_{1 \mathrm{i}}, E_{1 \mathrm{v}}$ and $E_{1 \mathrm{i}}$ are stored in a database indexed on relevant flow parameters. They were determined from the exact stability diagram of numerous Falkner-Skan similitudes profiles. The determination of the relevant parameters is explained in the next section.

\section{Determination of relevant flow parameters}

\section{A. Parabolas method for adiabatic wall}

The parabolas method developed by Arnal and all the extensions made after are valid for attached flows over adiabatic wall $\left(T_{\mathrm{w}} / T_{\mathrm{f}}=1\right)$. For this case, the relevant flow parameters used to index the database are the incompressible shape factor $H_{i}$ and the external Mach number $M_{\mathrm{e}}$. The $M_{\mathrm{e}}$ and $H_{i}$ variations allow to take compressible and pressure gradients effects into account, respectively [5]. It must be pointed out that a bijection exists between $H_{i}$ and the Hartree parameter $\beta_{\mathrm{H}}$.

Bégou [14] implemented the parabolas method into the RANS solver elsA. The determination of the boundary layer thickness $\delta$ allows to determine the $M_{\mathrm{e}}$ value as illustrated in Figure 5 Moreover when $\delta$ is known, the $H_{i}$ value can also be calculated. With these two values, the amplification rate $\sigma^{*}$ at the given station is assessed by the parabolas method.

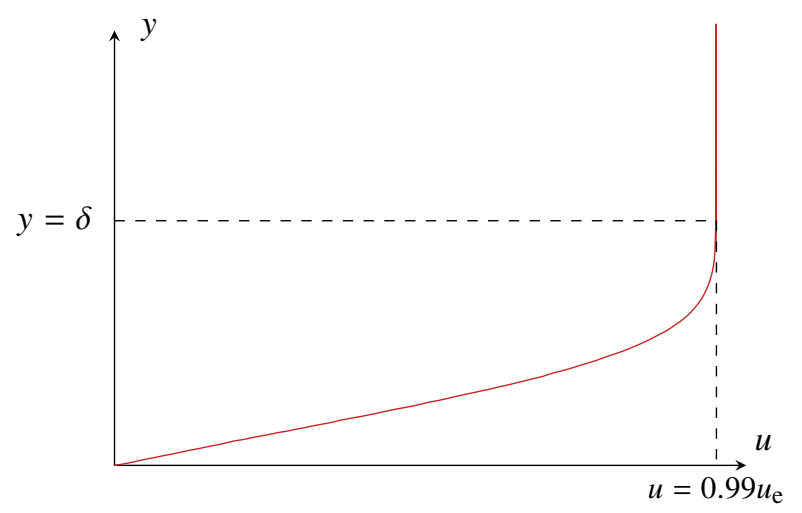

Fig. 5 Velocity profile from a RANS computation at a given station

A temperature correction has been developed but only for cold wall $\left(T_{\mathrm{w}} / T_{\mathrm{f}}<1\right)$. This correction consists in multiplying the coefficients used in the parabolas method by a correction function. As the temperature profile is not taken into account in this correction, an other strategyis chosen in the present paper for dealing with the heated wall configuration. 


\section{B. Parabolas method for heated wall}

When the wall is heated $\left(T_{\mathrm{w}} / T_{\mathrm{f}}>1\right)$, the compressible effect due to the change in air density has to be taken into account: the hypothesis $\rho=c s t$ is no longer valid. The database has then to be indexed by three parameters : one for the compressible effect, one for the pressure gradient effect and one for the temperature profile. The value of the three relevant flow parameters has to yield a single velocity and temperature profile.

The similitude profiles on which the extension of the database is built, are determined via a home made tool which solves similitude equations obtained with the Levy-Lee transformation [15]. Three parameters are useful to determine the profiles : the Mach number $M_{\mathrm{e}}$, the Hartree parameter $\beta_{\mathrm{H}}$ and the ratio $T_{\mathrm{w}} / T_{\mathrm{f}}$. With these three parameters, velocity and temperature profiles can be determine as illustrated in Figure 6.

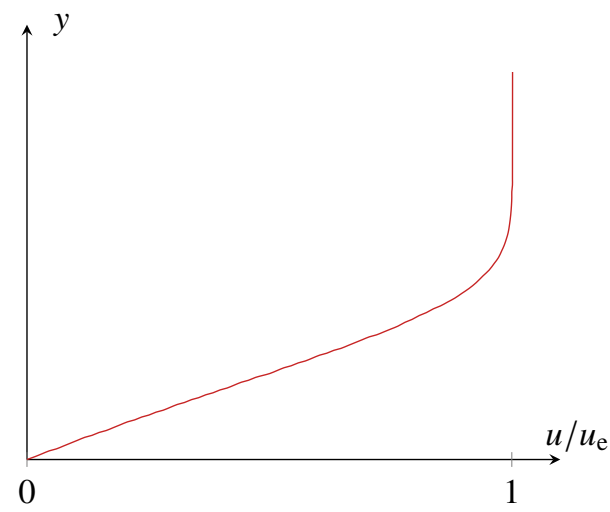

(a) Velocity profile

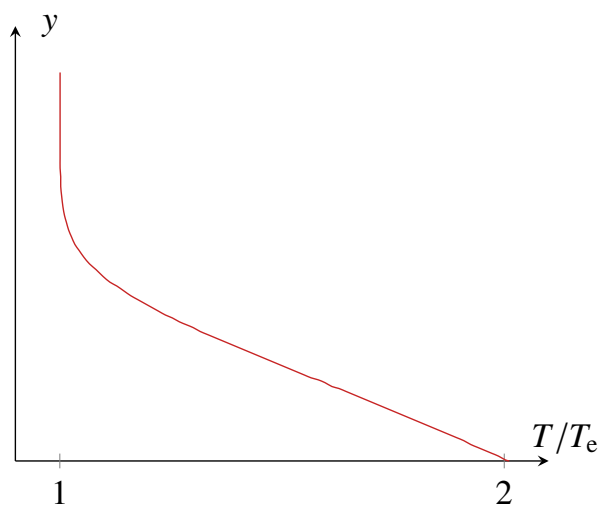

(b) Temperature profile

Fig. 6 Velocity and temperature profiles for $M_{\mathrm{e}}=0.18, \beta_{\mathrm{H}}=-0.01$ and $T_{\mathrm{w}} / T_{\mathrm{f}}=2.0$

We are now going to choose relevant paremeters for indexing the database. As in the adiabatic case, the compressible effect is taken into account by the external Mach number $M_{\mathrm{e}}$. The pressure gradient effect is no longer taken into account by the incompressible shape factor $H_{i}$ but by the similitude parameter $\frac{\mathrm{C}_{\mathrm{f}}}{2} \operatorname{Re}_{\theta_{11}}$, where $\mathrm{C}_{\mathrm{f}}$ is the skin friction coefficient and $\operatorname{Re}_{\theta_{11}}$ is the Reynolds number based on the momentum thickness $\theta_{11}$. Indeed, this yields better robustness in the context of RANS simulations.

The wall temperature effect can not be expressed by $T_{\mathrm{w}} / T_{\mathrm{f}}$ variations as a $T_{\mathrm{w}} / T_{\mathrm{f}}$ value does not represent the shape of the temperature profile : for the similitude tool $T_{\mathrm{w}} / T_{\mathrm{f}}$ is a boundary condition. A parameter similar to $\frac{\mathrm{C}_{\mathrm{f}}}{2} \operatorname{Re}_{\theta_{11}}$ derived from the temperature profile is thus looked for.

In the litterature [8], the global energy equation can be written as

$$
\frac{\Phi_{w}}{\rho_{\mathrm{e}} u_{\mathrm{e}} h_{i e}}=\frac{1}{\rho_{\mathrm{e}} u_{\mathrm{e}}} \frac{d}{d x}\left(\rho_{\mathrm{e}} u_{\mathrm{e}} \Delta\right)
$$

The enthalphy tickness $\Delta$ can be calculated as follow

$$
\Delta=\int_{0}^{\delta} \frac{\rho u}{\rho_{\mathrm{e}} u_{\mathrm{e}}}\left(\frac{h_{i}}{h_{i e}}-1\right) \mathrm{dy}
$$

The left side of 20p defines a heat flux coefficient $C_{h}$

$$
\mathrm{C}_{\mathrm{h}}=\frac{\Phi_{w}}{\rho_{\mathrm{e}} u_{\mathrm{e}} h_{i e}}
$$

A Reynolds number, denoted as $\operatorname{Re}_{\Delta}$, can be created from the enthalphy thickness, the velocity and the viscosity at the boundary layer edge. The interesting parameter is then $C_{h} R_{\Delta}$.

As it is well known that there is a bijection between $\beta_{\mathrm{H}}$ and $\frac{\mathrm{C}_{\mathrm{f}}}{2} \operatorname{Re}_{\theta_{11}}$ [8], a bijection relation has to exist between $T_{\mathrm{w}} / T_{\mathrm{f}}$ and $\mathrm{C}_{\mathrm{h}} \mathrm{Re}_{\Delta}$ to validate the choice of this parameter. 


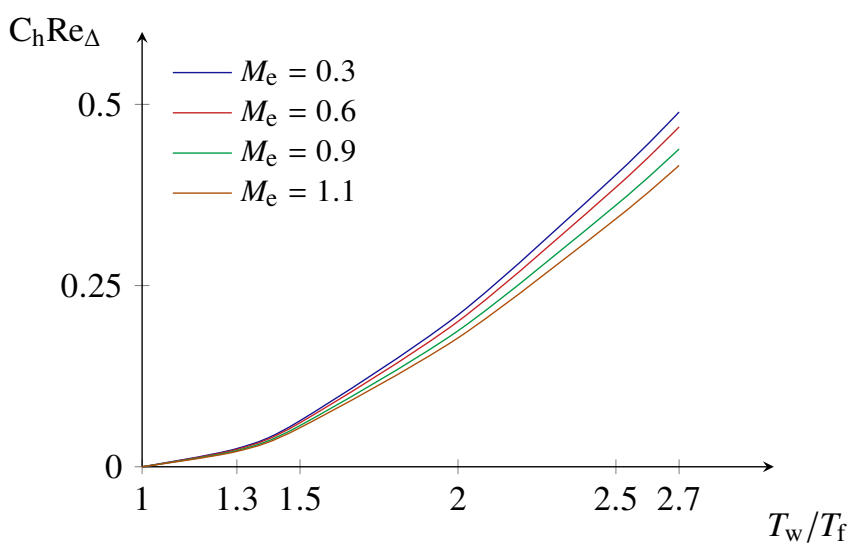

Fig. $7 \quad C_{\mathrm{h}} \operatorname{Re}_{\Delta}$ evolution for different $T_{\mathrm{w}} / T_{\mathrm{f}}$ ratios and for a flat plate $\left(\beta_{\mathrm{H}}=0\right)$

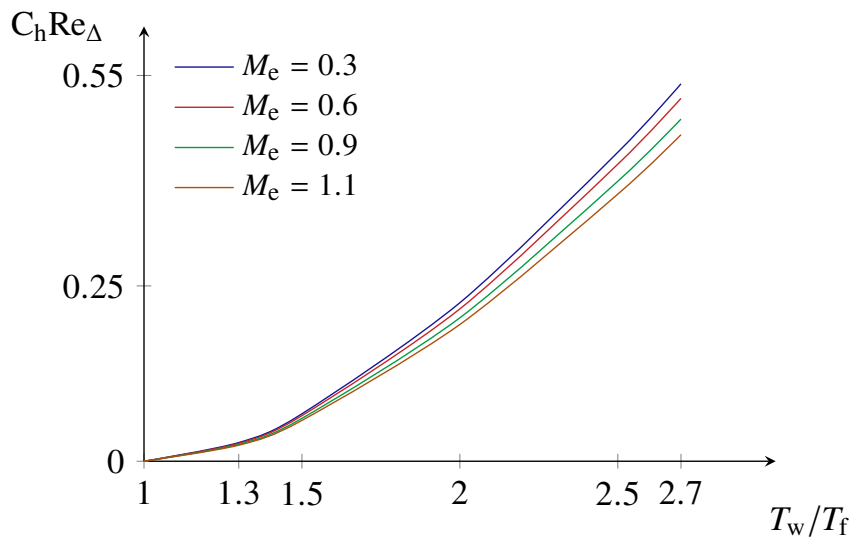

Fig. $8 \mathrm{C}_{\mathrm{h}} \mathrm{Re}_{\Delta}$ evolution for different $T_{\mathrm{w}} / T_{\mathrm{f}}$ ratios and for $\beta_{\mathrm{H}}=0.05$

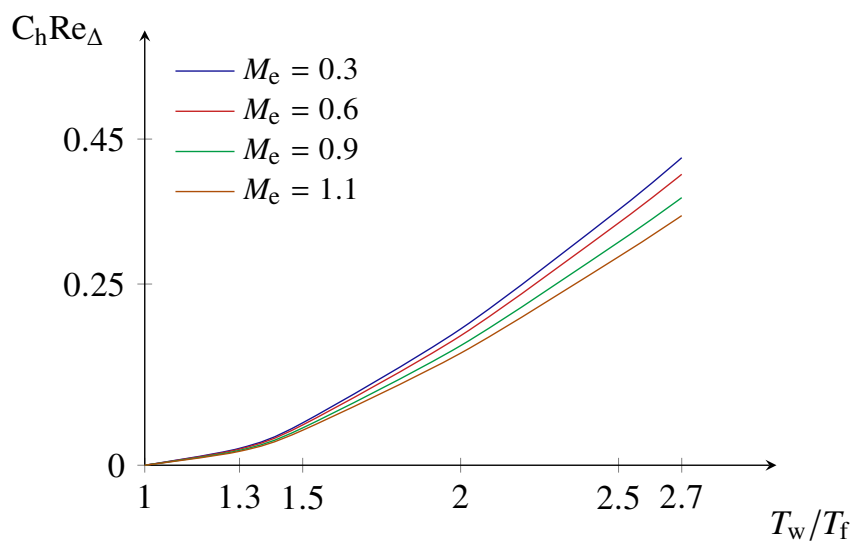

Fig. $9 \mathrm{C}_{\mathrm{h}} \mathrm{Re}_{\Delta}$ evolution for different $T_{\mathrm{w}} / T_{\mathrm{f}}$ ratios and for $\beta_{\mathrm{H}}=-0.05$

Figures 7, 8, 9 can justify the existence of a bijection relation as for a fixed Mach number $M_{\mathrm{e}}$ value and a fixed $T_{\mathrm{w}} / T_{\mathrm{f}}$ value there is only one $C_{h} \operatorname{Re}_{\Delta}$ value and conversely.

To sum up, the three relevant parameters to index the database for a flow over a heated wall are $: M_{\mathrm{e}}, \frac{\mathrm{C}_{\mathrm{f}}}{2} \operatorname{Re}_{\theta_{11}}$ and $\mathrm{C}_{\mathrm{h}} \mathrm{Re}_{\Delta}$.

\section{Database first results}

The home made similitude tool gives a single velocity profile and a single temperature profile for a set of parameters $\left(M_{\mathrm{e}}, \beta_{\mathrm{H}}\right.$ and $\left.T_{\mathrm{w}} / T_{\mathrm{f}}\right)$. Local linear stability equations can be solved for these two profiles : the evolution of $\sigma^{*}$ exact can be determined as a fonction of $\operatorname{Re}_{\delta_{1}}$. Figure 10 illustrates this evolution for $M_{\mathrm{e}}=0.3, \beta_{\mathrm{H}}=0$ and $T_{\mathrm{w}} / T_{\mathrm{f}}=2.7$ and compares it with the evolution of $\sigma^{*}$ parab given by the parabolas method. As expected, a very good match is obtained.

The previous set of parameters corresponds to $\left(M_{\mathrm{e}}, \frac{\mathrm{C}_{\mathrm{f}}}{2} \operatorname{Re}_{\theta_{11}}, \mathrm{C}_{\mathrm{h}} \operatorname{Re}_{\Delta}\right)=(0.3,0.2005,0.4895)$.

For the construction of the database, 150 similitude profiles have been used : $M_{\mathrm{e}} \in\{0,1.3\}$ with 5 points, $\beta_{\mathrm{H}} \in$ $\{-0.065,0.2\}$ with 6 points and $T_{\mathrm{w}} / T_{\mathrm{f}} \in\{1,2.7\}$ with 5 points. 


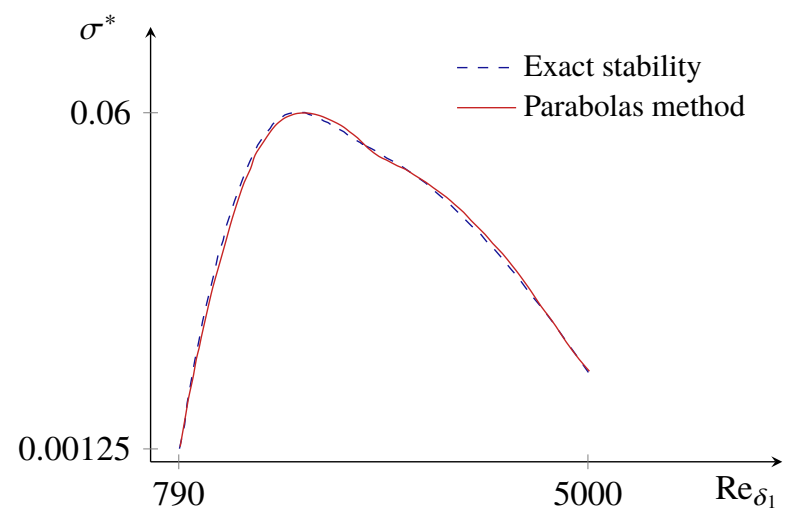

Fig. 10 Evolution of $\sigma^{*}$ for $M_{\mathrm{e}}=0.3, \beta_{\mathrm{H}}=0$ and $T_{\mathrm{w}} / T_{\mathrm{f}}=2.7$

\section{Numerical validation}

The numerical validation, carried out with the RANS solver elsA (jointly owned by Airbus-Safran-ONERA), will be done in the final on an ONERAD airfoil with a heated skin. Experimental results are available for this configuration [16] with some measurements of the transition location. This configuration was tested in the F2 wind tunnel at ONERA (Fauga-Mauzac).

Moreover, comparaisons with exact stability calculations will be made to validate the computation of the amplification rates obtained by the database approach applied to the $(u, T)$ profiles obtained in the RANS simulations.

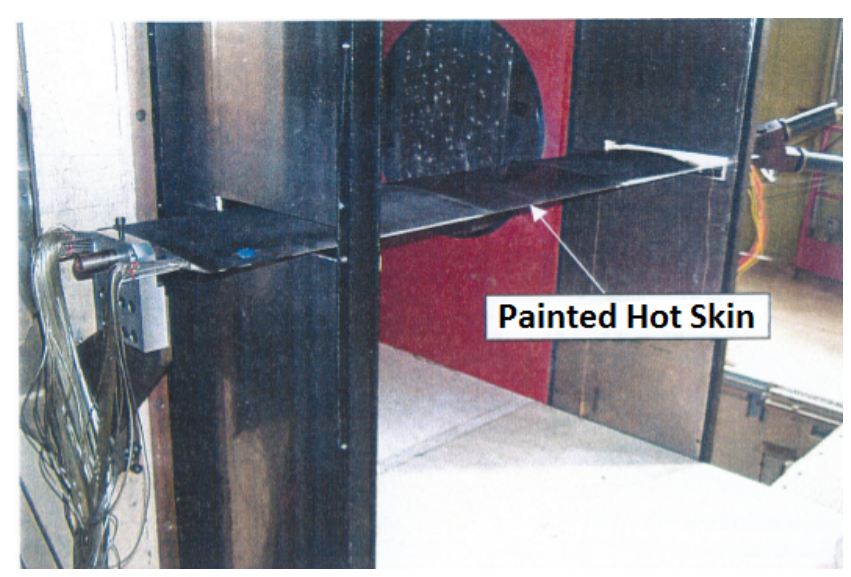

Fig. 11 ONERAD airfoil experimental setup with hot skin in ONERA F2 wind tunnel

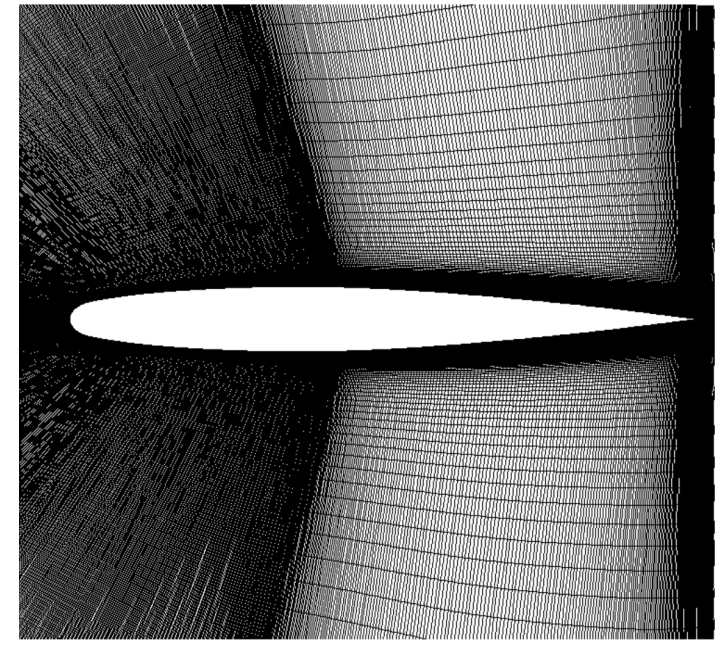

Fig. 12 Mesh around ONERAD airfoil

\section{References}

[1] Van Ingen, J., "The eN method for transition prediction. Historical review of work at TU Delft," 38th Fluid Dynamics Conference and Exhibit, 2008, p. 3830.

[2] Reed, H., Saric, W., and Arnal, D., "Linear stability theory applied to boundary layer," Annual Review of Fluid Mechanics, Vol. 28, No. 1, 1996, pp. 386-428.

[3] Van Ingen, J., "A suggested semi-empirical method for the calculation of the boundary layer transition region," Technische Hogeschool Delft, Vliegtuigbouwkunde, Rapport VTH-74, 1956.

[4] Smith, A., and Gamberoni, N., "Transition, pressure gradient and stability theory,", 1956.

[5] Arnal, D., "Transition prediction in transonic flow," Symposium Transsonicum III, Springer, 1989, pp. $253-262$. 
[6] Perraud, J., Arnal, D., Casalis, G., Archambaud, J., and Donelli, R., “Automatic transition predictions usign simplified methods," AiAA Journal, Vol. 47, 2009, pp. 2676-2684.

[7] Arnal, D., "Développement d'une méthode simplifiée de calcul des instabilités de couche limite en écoulement supersonique," Tech. rep., DERAT, 1995.

[8] Cousteix, J., Aérodynamique : Couche limite laminaire, Edition CEPADUES, 1988.

[9] Mack, L., "Boundary-layer linear stabiliy theory,” AGARD report No.709, 1984.

[10] Arnal, D., and Casalis, G., "Laminar-turbulent transition prediction in three-dimensional flows," Progress in Aerospace Sciences, Vol. 36, No. 2, 2000, pp. 173-191.

[11] Morkovin, M., “On the many faces of transition,” Viscous drag reduction, Springer, 1969, pp. 1-31.

[12] Prandtl, L., "Bemerkungen über die Entstehung der Turbulenz," Journal of Applied Mathematics and Mechanics, Vol. 1, No. 6, 1921, pp. 431-436.

[13] Lees, L., and Lin, C., "Investigation of the stability of the laminar boundary layer," Tech. rep., California Institute of Technology, 1946.

[14] Bégou, G., "Prévision de la transition laminaire-turbulent dans le code elsA par la méthode des paraboles," Ph.D. thesis, ISAE, 2017.

[15] Levy, S., "Effect of large temperature changes (including viscous heating) upon laminar boundary layers with variable free-stream velocity," AIAA, 1954.

[16] Séraudie, A., Arnal, D., and Rodde, A., "Effet d'un chauffage de paroi sur la transition laminaire-turbulent (transition naturelle et transition déclenchée)," Tech. rep., ONERA-DMPE, 2003. 